\title{
Factors Affecting Assertive Behaviour among Head nurses
}

Shaimaa Mossad Hussien Ali ${ }^{1}$;

Mona Mostafa Shazly 2; Safaa Mohammed Abd Elrahman 3

1 B. Sc in Nursing, Minia University, Egypt .

2 Professor of Nursing Administration , Faculty of Nursing - Ain -Shams University; Egypt .

3 Assistant Professor of Nursing Administration, Faculty of Nursing - Minia Universit, Egypt .

Abstract

Assertiveness is the expression of one's feelings, beliefs, opinions, needs in a direct, honest and appropriate manner. Assertive not describe individual only also describe behavior, so that assertive behavior is a behavior which directly expresses individual's true, basic feelings, needs, desires, opinions and personal rights in a positive, productive way without denying the rights of others. The aim of the study: Identifying the factors affecting assertive behaviour among head nurses at Minia University Hospitals. Research design: Descriptive research design was used in this study. Setting: This study was carried out at Minia University Hospitals. Sample: Convenient sample of all available head nurses in Minia University Hospitals with total number ( $\mathrm{n}=$ 50). Tool: Selfadministrated questionnaire sheet which was consisted of two parts: Part (1): Demographic data \&Part (II): Factors affecting Assertive Behaviour Questionnaire. Results: Two thirds of head nurses have high assertive behaviour regarding to communication domain but they have low assertiveness in other domains. There were statistical significance difference between communication, rights and responsibilities, and assertiveness as a total and female gender. Conclusions: This study concluded that all head nurses had low assertiveness level. There were no statistical significance differences between head nurses' assertiveness and their socio-demographic Recommendation: Study other factors affecting assertive behaviour such as personality, experience, attitude and beliefs. Further researches to investigate the socio cultural circumstances that may hinder or enhance the individual to be assertive.

Keywords: Assertive behaviour, Head nurses.

\begin{tabular}{|c|c|}
\hline Introduction & Lack of assertiveness can lead to depression from \\
\hline Head nurses in Current healthcare environments & anger turned inward, resentment, frustration, anxiety, which \\
\hline need become to be more aware of how use assertiveness & leads to avoidance, poor relati \\
\hline effectively in their workplaces to manage the challenges & assertive people are often unable to express emotions of any \\
\hline their face when dealing with human resources. Head nurses & kind, and always isolated ${ }^{(8)}$. Nonassertive head nurse often \\
\hline are traditionally regarded as being in subservient roles and & attempts to avoid problem by $r$ \\
\hline as having to live up to public expectations . The pressure of & angry, she can't face \\
\hline these expectations is thought to reduce a their capacity to & without taking pro \\
\hline $\begin{array}{l}\text { behave in an assertive manner }{ }^{(1)} \text {. They } r \\
\text { competence of clinical grasp and clinical fore }\end{array}$ & for \\
\hline $\begin{array}{l}\text { competence of clinical grasp and } \mathrm{cl} \\
\text { providing patient appropriate care. Fu }\end{array}$ & $\begin{array}{l}\text { critical situations which need } \\
\text { action at proper time }{ }^{(9)} \text {. }\end{array}$ \\
\hline
\end{tabular}
are expected to show clinical leadership at the patient bedside to provide direction and support to patients and health care team for integrating the care they provide to achieve positive patient outcomes. So that they assert their opinions to other team members for changing the care plan for their patients ${ }^{(2)}$.

Assertiveness is referred to as an ability to convey feelings, beliefs, and thoughts without anxiety and to express personal rights without denying the rights of others. It contributes to accept the responsibility of behavior, helping in increase self-esteem and selfconfidence $^{(3)}$. Furthermore assertiveness is usually used to describe both behaviors and individuals. such as a highly assertive person refer to someone who was seen by others as habitually acting in a highly assertive way and it was described as expressing thoughts and feelings without denying the rights of others ${ }^{(4,5)}$.

Assertive behaviors is the ability to stand up for the rights and expresses the personal needs, values, concerns and ideas in direct and appropriate ways, assertive people meeting their needs, without violating the needs of others or trespass on other personal space. They communicate with others by using direct sentences, maintain eye contact, and use appropriate distance, head nods and lean forward to listen attentively to the speaker. So that assertiveness is a key attribute for head nurses without it true autonomy and personal empowerment cannot be achieved thus it is considered to be an essential skill for them ${ }^{(6,7)}$.

\section{Significance of the study:}

Assertive is consider to be healthy and desirable behavior for all people who interact in group situation, head nurses in multidisciplinary care show that they are rarely asked for their opinions during health team meeting and conversations. These conversations demonstrate a degree of lack of assertiveness. One study reported that in general individuals are not highly skilled in expressing their own needs which is at the core of assertive behaviour ${ }^{(10)}$. Other study stated that head nurses and nurse managers frequently did not express their opinions or provides constructive criticism and suggestions in nursing practice $^{(11)}$. So that head nurse needs to be assertive in the clinical field and confident in professionally relationships and skills, also assertiveness increases self-worth and decrease helplessness and hopelessness ${ }^{(12)}$. Thus this study will describe factors affecting assertive behaviour among head nurses in their work .

\section{Aim of the study}

Identifying the factors affecting assertive behaviour among head nurses at Minia University Hospitals.

\section{Research Question}

What are the factors affecting assertive behaviour among head nurses at Minia University Hospitals? 


\section{Subjects and Methods \\ Research design:}

Descriptive design was utilized in current study to achieve the aim of the study.

\section{Research Setting:}

The study was conducted at Minia University Hospitals, which include four different hospitals, (Minia university hospital, Obstetric \& Gynecology and Pediatric hospital, Renal urology hospital, and Cardiothoracic hospital) in Minia Governorate.

Sample

Convenient sample of all available head nurses in Minia University Hospitals were included in this study, with total number $(\mathrm{n}=50)$.

\section{Tools of data collection:}

Data for this study was collected by using one tool. Self-administrated questionnaire sheet (Factors Assertive Behaviour). Which classified into two parts:-

- Part I: Socio-demographic data sheet, to get information about head nurses working at Minia University Hospitals includes (name, age, gender, marital status, qualification and years of experience)

- Part (II): (Factors Assertive Behaviour questionnaire). This tool aimed to identify factors affecting assertive behaviour among head nurses. It was developed by Rasetsoke, (2012) ' and translated into arabic by the researcher. It consisted of 56 questions, which were grouped under four factors as follows: Communication skills factor (16 questions), Personal / Professional rights and responsibilities factor (12 questions), Conflict factor (14 questions) and Self-confidence factor (14 questions).

\section{Scoring system:}

The questionnaire containing 56 questions with a 5-point likert scale. This questions were scored 1, 2, 3, 4 and 5 for the responses Never, Rarely, Neutral, Often, and Always, respectively. For each factor, the scores of items were summed-up and the total divided by number of the items giving a mean score for factor. These scores were converted into a percent score. Head nurses considered high assertive if the percent score was $60 \%$ or more, and head nurses considered low assertive if the percent score Less than $60 \%$.

\section{Validity}

$$
\begin{aligned}
& >\quad 60 \% \text { and more }---------- \text { High assertive. } \\
& >\quad \text { Less than } 60 \% \text {-------- Low assertive }
\end{aligned}
$$

Study tool was reviewed by three experts، two of them are assistant professors of nursing administration in Faculty of Nursing، Assuit University، one assistant professor of nursing administration in Faculty of Nursing،
Minia University. Based on experts comments and recommendations of thesis supervisors minor changes had been made in the questionnaire .

\section{Reliability}

The tool was designed in it is final format and tested for reliability by using, cronbach's alpha coefficient test (0.82). the tool proved to be reliable.

Pilot study

A pilot study was carried out on approximately (10 $\%$ ) of the study sample in a selecting setting to evaluate the applicability \& clarity and feasibility of the study tool and to estimate the time needed for filling the tool that ranged between 15 to 30 minute . As well as, identifying problems that may be encountered during actual data collection. Result of the pilot study illustrated that no modification needed so that the pilot sample study was included in the main study sample.

\section{Study procedure}

An official letter of the study approved was obtained from Dean of Faculty of Nursing -Minia University to the manager of the hospitals. This letter was including a brief explanation of the objective of the study. After receiving the initial acceptance from the ethical committee at the Faculty of Nursing, Minia University, the researcher initially introduced herself to all participants to explain the aim of the study and to obtain their permission. They were assured that the collected data would be absolutely confidential. Data were collected in the period from February 2016 until June 2016. The researcher collected the data during the morning at two days/week from 10 AM to 12 PM.

\section{Ethical consideration:}

A written initial approval obtained from the research ethical committee in the Faculty of Nursing, Dean of Nursing Faculty and agreement from Egypt academic for research center and technology. participants in this study were voluntary and informed about the purpose, procedure of the study and the right to withdraw from the study at any time without any rational. Written consent were obtained from the subjects after reading all details. Confidentiality and anonymity of each subjects were ensured through coding of all data and protecting the obtained data .

\section{Statistical design}

Data entry and statistical analysis were done using a Statistical Sackage for Social Science (SPSS), version (16).Data were presented using descriptive statistics in the form of frequencies and percentages, mean and standard deviations. Cronbach alpha coefficient was calculated to assess the reliability of the developed tool through their internal consistency. Probability ( $p$-value) is the degree of significance, if it less than 0.05 was considered significance, the more significance is the result $\left(^{*}\right)$, less than 0.001 was considered highly significance $(* *)$ and correlation coefficient was done by using Spearman rank correlation. 


\section{Results}

Table (1): Socio-demographic characteristics of head nurses in the study sample $(n=50)$.

\begin{tabular}{|l|c|c|}
\hline \multicolumn{1}{|c|}{ Personal and socio demographical Data } & Prequency & \\
\hline 1. Age & & 68.0 \\
$<31$ & 34 & 32.0 \\
$31+$ & 16 & 8.0 \\
\hline 2. Gender: & 4 & 92.0 \\
Male & 46 & 18.0 \\
Female & 9 & 82.0 \\
\hline 3. Marital status & 41 & \\
Unmarried & & 98.0 \\
Married & 49 & 2.0 \\
\hline 4. Nursing qualifications & 1 & 18.0 \\
Bachelor & & 48.0 \\
Master & 24 & 34.0 \\
\hline 5. Experience years & 17 & \\
$<5$ & & \\
5- & & \\
$10+$ & & \\
\hline
\end{tabular}

Table (1): Revealed that two thirds of study sample their age were more than thirty one years. majority of the study sample were femalse $(92 \%)$, more than three quarters of head nurses were married $(82 \%)$, and the majority of head nurses were have bachelor degree (98\%) .Finally regarding to years of experience nearly to half of head nurses $(48 \%)$ had experience between 5 to less than 10 years.

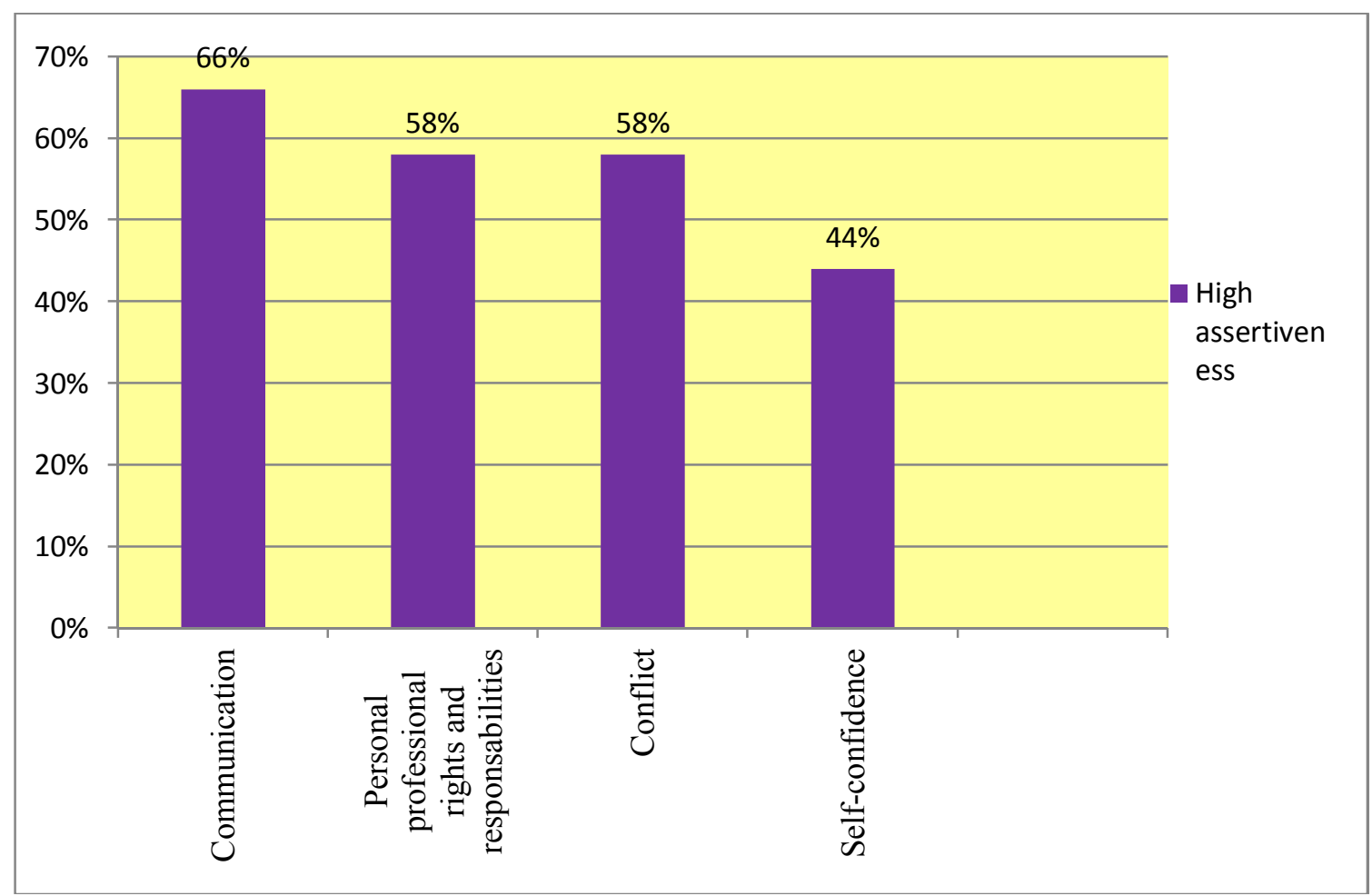

Fig. (1) Distribution of level of high assertiveness among head nurses $(n=50)$

Figure (1): Illustrated that two thirds of head nurses have high assertiveness regards communication (66\%), but have low assertiveness in personal/ professional rights and responsibility, conflict , and self - confidence (58\%, 58\%, 44\% respectively ). 


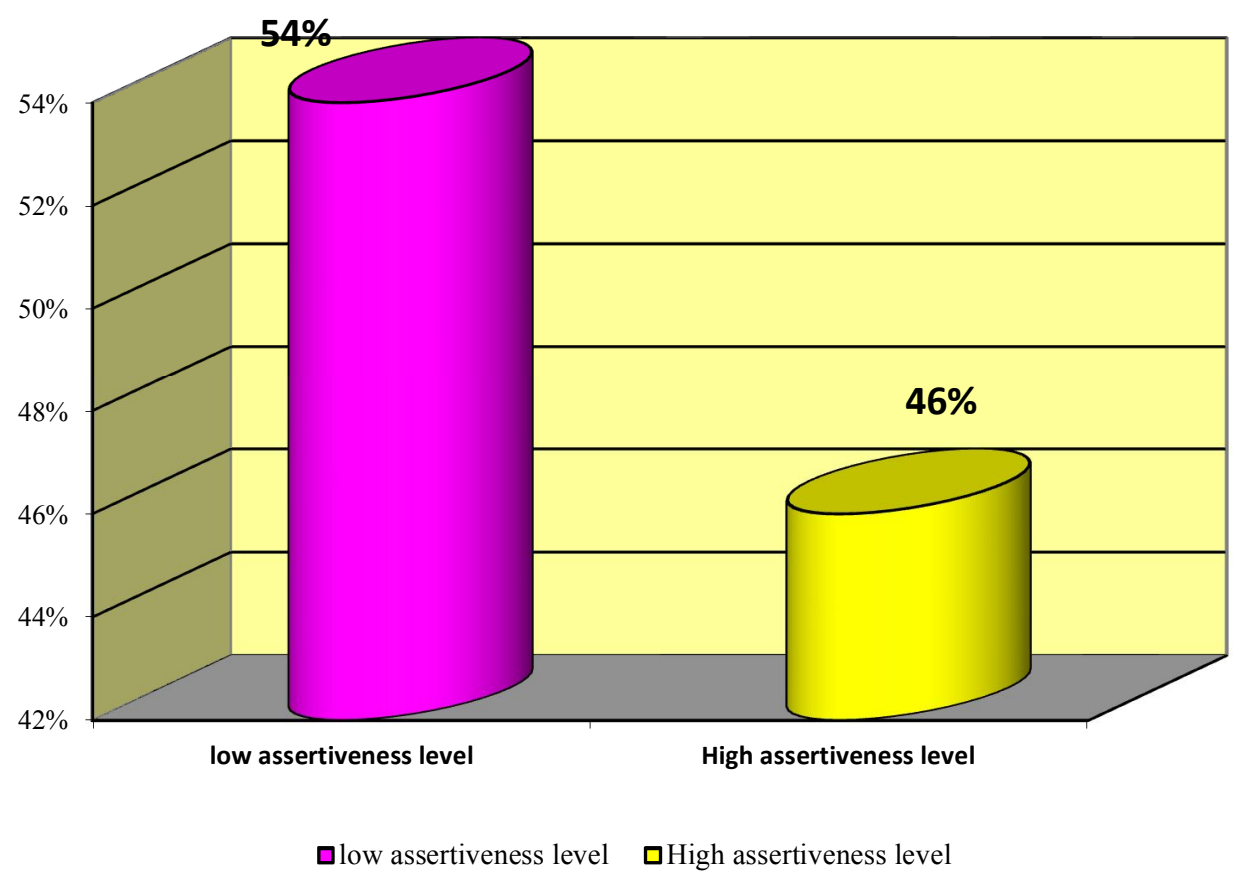

Fig. (2) Distribution of assertiveness level among head nurses ( $n=50$ )

Figure (2) : Illustrated that more than half of study sample (54\%) have low level of assertiveness compared with less than half of them (46\%) have high level of assertiveness, which indicated that there was low assertiveness level in all study sample.

Table (2): Relations between head nurses total assertiveness and their socio-demographic characteristics $(n=50)$

\begin{tabular}{|c|c|c|c|c|c|c|}
\hline \multirow{3}{*}{ Socio demographic characteristics } & \multicolumn{4}{|c|}{ Total assertiveness $(n=50)$} & \multirow{3}{*}{ Fisher } & \multirow{3}{*}{ p-value } \\
\hline & \multicolumn{2}{|r|}{ High } & \multicolumn{2}{|r|}{ Low } & & \\
\hline & No. & $\%$ & No. & $\%$ & & \\
\hline $\begin{array}{l}\text { 1. Age } \\
<31 \\
31+\end{array}$ & $\begin{array}{l}18 \\
9\end{array}$ & $\begin{array}{l}52.9 \\
56.3\end{array}$ & $\begin{array}{l}16 \\
7\end{array}$ & $\begin{array}{l}47.1 \\
43.8\end{array}$ & $=0.05^{X^{2}}$ & $0.83(\mathrm{NS})$ \\
\hline $\begin{array}{l}\text { 2. Marital status } \\
\text { Unmarried } \\
\text { Married }\end{array}$ & $\begin{array}{l}5 \\
22 \\
\end{array}$ & $\begin{array}{l}55.6 \\
53.7 \\
\end{array}$ & $\begin{array}{l}4 \\
19 \\
\end{array}$ & $\begin{array}{l}44.4 \\
46.3 \\
\end{array}$ & 1.61 & 1.00 \\
\hline $\begin{array}{l}\text { 3. Nursing qualification } \\
\text { Bachelor } \\
\text { Master }\end{array}$ & $\begin{array}{l}26 \\
1\end{array}$ & $\begin{array}{l}53.1 \\
100.0\end{array}$ & $\begin{array}{l}23 \\
0\end{array}$ & $\begin{array}{l}46.9 \\
0.0\end{array}$ & 2.52 & 1.00 \\
\hline $\begin{array}{l}\text { 4. Experience years } \\
<5 \\
5- \\
10+\end{array}$ & $\begin{array}{l}5 \\
14 \\
8\end{array}$ & $\begin{array}{l}55.6 \\
58.3 \\
47.1\end{array}$ & $\begin{array}{l}4 \\
10 \\
9\end{array}$ & $\begin{array}{l}44.4 \\
41.7 \\
52.9\end{array}$ & 3.52 & $0.77(\mathrm{NS})$ \\
\hline
\end{tabular}

NS.... Not Significant

Table (2): Found that there were no statistical significance differences between head nurses' total assertiveness and their socio demographic in which p- value $>0.05$.

Table (3) Best fitting multiple linear regression model for total assertiveness score.

\begin{tabular}{|c|c|c|c|c|c|c|c|}
\hline \multirow{2}{*}{ Items } & \multicolumn{2}{|c|}{$\begin{array}{r}\text { Unstandardized } \\
\text { Coefficients }\end{array}$} & \multirow{2}{*}{$\begin{array}{r}\text { Standardized } \\
\text { Coefficients }\end{array}$} & \multirow{2}{*}{ t-test } & \multirow{2}{*}{$\mathrm{p}$-value } & \multicolumn{2}{|c|}{$\begin{array}{l}95 \% \text { Confidence } \\
\text { Interval for B }\end{array}$} \\
\hline & B & Std. Error & & & & Lower & Upper \\
\hline Constant & 95.47 & 7.75 & & 12.319 & $<0.001$ & 79.89 & 111.05 \\
\hline Female gender & -8.25 & 4.00 & -0.29 & -2.063 & 0.045 & -16.28 & -0.21 \\
\hline
\end{tabular}

Variables entered and excluded: age, marital status, qualification, job position, experience

Table (3): showed that there was statistical significance difference between total assertiveness and female gender in which $\mathrm{p}$ - value $<.045$.

\section{Discussion}

Assertiveness is an important behaviour for today's professional nurse. As nurses move away from traditional subservient roles and perceived stereotypes. It is increasingly being recognized that a nurse needs to behave $P$ a g e $\mid 4$ in an assertive manner. Furthermore it is necessary for effective nurse-patient communication. $\operatorname{McCabe}(2003)^{(13)}$ suggested that assertiveness development may also aid in building the confidence of the profession as it develops. Assertive behaviour is encouraged through educational Shaimaa M., et al 
methods. It is preferable that nurses receives this educational preparation during undergraduate programmes.

This study showed that two thirds of study sample their age group less than thirty one years. The majority of the samples were females $(92 \%)$, and more than three quarter( $82 \%)$ of sample were married, while very few head nurses $(18.0 \%)$ were unmarried. As regarding to level of education the majority of them have bachelor degree. Regarding to experience nearly to half of head nurses $(48.0 \%)$ have experience between 5 to less than 10 years .

The findings of the present study indicated that two thirds of the head nurses ( $66 \%$ ) have high assertiveness regards communication, but have low assertiveness in personal/ professional rights and responsibility ( 58\%), conflict $58 \%$ ) and self confidence( $44 \%)$. This result was due to assertive behaviour and good communications are inextricably linked. Also assertive behaviour requires effective communication.Good communication skills that they use and present of cooperation and love between team members that make them more active and motivated to improve quality of health services to reach to the complete nursing care.

This result were in the same line withEl$\operatorname{deep}(2014)^{(14)}$ who evaluated assertiveness and stress among undergraduate nursing students at menofyia university, and reported that being assertive is a core communication skill which is learnable like any other skills, and this means that the person are capable of expressing self effectively and stand up for point of view to get accepted while without being aggressive and respecting the feelings of others. Also result were consistent with Maheshwari et al. , $(2015)^{(15)}$ who analysis correlation of assertive behavior with communication satisfaction among nurses in India, reported that assertive behavior has large positive correlation with interpersonal communication satisfaction and their results indicated that increasing in assertive behavior associated with increasing interpersonal communication satisfaction.

This study showed that more than half of head nurses $(54 \%)$ have low level compared with less than half of them $(46 \%)$ have high levels of assertiveness, which indicated that there was low assertiveness level among study sample, this result consistent with the study of Rasetsoke $(2012)^{(1)}$ who assessed assertive behaviour of professional nurses and nurse managers in unit management at academic hospital settings in the pretoria region and reported that some of professional nurses and nurse managers in academic hospitals in the Pretoria region had shortage in assertive behaviour skills.

On the contrary with the result of Abdel-aleem $(2007)^{(16)}$ who studied factors affecting assertiveness among head nurses and staff nurses at Faculty of Nursing, Suez Canal University and found that the majority of both the head nurses as well as nurses are assertive, also the result of El-Din(2003) $)^{(17)}$ who studied factors affecting assertive behavior of nurses working in different units in Cairo university hospitals, and result of Ahmed (2009) ${ }^{(18)}$ who assessed assertiveness and job satisfaction among nursing personnel at zagazig university hospital they found that the majority of their sample were highly and moderately assertive.

The finding of present study indicated that there were no statistical significance differences between total head nurses' assertiveness and their socio demographic data.
So that their were no statistical significant relation between assertiveness and age. This result may be because assertiveness is a part of the human personality since childhood, and there are some factors that contribute to elevate the level of assertiveness, such as personality traits, beliefs and attitudes throughout life. This result is consistent with the result of Sanders $(2007)^{(19)}$ who assessed assertive communication skills with nurses in a rural setting at university of Wyoming, and with the result of Ahmed $(2009)^{(18)}$ they reported that there were no statistical significance differences between nursing personnel assertiveness level and their age.

On the contrary, with the result of El-Din(2003) ${ }^{(17)}$ who reported that there was a statistical significant difference of nursing personnel assertiveness level and their age, also Abdel-khalek(2010) ${ }^{(20)}$ who assessed level of assertiveness and nursing performance in Faculty of nursing, Cairo University they reported that there were a statistical significant difference of nursing personnel assertiveness level and their age. Also Eskin(2003) ${ }^{(21)}$ who evaluated selfreported assertiveness in Swedish and Turkish adolescents they found that older nurses had higher assertiveness level than younger ones.

Relating to years of experience, the result of the present study showed that there is no statistical significant relation between assertiveness and years of experience, which is consistent with Kilkus (2010) $)^{(23)}$ who assessed assertiveness among professional nurses and found that no significant differences between assertiveness level and length of years' experience. On the contrary to Khalil $(2011)^{(24)}$ who studied assertive behavior among nursing working in critical units at Ain Shims University Hospitals indicated that a highly significant relation between assertiveness level and nursing years of experience, this finding is supported byAbdel-khalek(2010) ${ }^{(20)}$ who found that most experienced nurse managers had the highest assertive level, also with the result of Ahmed(2009) ${ }^{(18)}$ who stated that the oldest and most experienced groups of nurses and nurse managers were the least assertive.

The present study indicated that there were no significant statistical differences between head nurses's assertiveness level with marital status. This finding is consistent with Abdel-aleem $(2007){ }^{(16)}$ who found that there were no statistically significant differences between level of assertiveness and marital status. This finding opposed with result of El-Din(2003) ${ }^{(17)}$ who indicated that the level of assertiveness was much higher among single nurse manager than other statuses. Ahmed(2009) ${ }^{(18)}$ showed that widows had the highest mean of assertiveness.

According to nursing qualification of the present study which indicated that there were no significant statistical differences between level of assertiveness and nursing qualifications. This finding may be due to majority of study sample were head nurses, also due to that head nurses with life patterns and their responsibilities whatever in work or home makes them have stronger assertiveness communication skills. This finding is consistent with Abdel-aleem $(2007)^{(16)}$ who reported that there was no statistical significance between level of education and level of assertiveness. But was inconsistent with Ahmed(2009) ${ }^{(18)}$ who found that the highest assertiveness mean scores present at the baccalaureate nurses followed by associated degree, while the lowest mean scores were present at diploma school degree. Also Sanders $(2007)^{(19)}$ which 
concluded that there was a positive association between stronger assertiveness and higher educational levels.

The current study revealed that there was statistical significance difference between total assertiveness and female gender. This result is consistent with Eskin(2003) ${ }^{(21)}$ who stated that in general girls were found to be skilled in expressing and dealing with personal limitation and more assertive than boys. This result is inconsistent with result of Abed et al ., (2015) ${ }^{(25)}$ evaluated the effect of assertiveness training program on improving self-esteem of psychiatric nurses and indicated that there was no statistically significant difference between sex and total assertiveness skills. This result was may be due to increase the number of female nursing working as the head nurses

\section{Conclusion}

Based on the finding of this current study, it was concluded that:

- Result indicated that about two thirds of head nurses had high assertiveness regarding to communication but they had low assertiveness in personal/ professional rights and responsibility, conflict, and self - confidence. Result indicated that communication \& personal / professional rights and responsibilities among the study sample have the highest mean score, while self- confidence has the lowest mean score.. More than half of head nurses (54\%) have low level of assertiveness compared with less than half of them $(46 \%)$ have high level of assertiveness, which indicated that there was low assertiveness level among study sample.

\section{Recommendations:}

Based on results of the present study the following can be recommended:

- Use of assertiveness training program for all nurses to improve and enhance their self-esteem and assertiveness.

- The concepts of assertiveness, assertiveness technique should be included in basic undergraduate nursing curriculum.

- Nurse educators have an important role in the development and implementation of assertiveness training/education program for undergraduate nursing students.

- Head nurses must be continued development of communication and interpersonal teaching to improve her staff communication skills .

- Role-play can form a vital component of displaying and teaching assertiveness skills. However, further research is required on role-play to ascertain methods of best practice for head nurses.

- Teaching assertiveness skills is of particular interest to the nurse educator as it is preferable that nurses receive adequate preparation during their undergraduate education.

- Study other factors that affecting assertiveness such as personality, experience, attitude and beliefs which need further researches

- Further researches to investigate the socio cultural circumstances that may hinder or enhance the individual to be assertive.

\section{References}

1- Rasetsoke RL. Assertive Behaviour of Professional Nurses and Nurse Managers in Unit Management at Academic Hospital Settings in the Pretoria Region .University of Johannesburg. 2012:121123.

2- Okuyama A, Wagner C, Bijnen B. How We Can Enhance Nurses' Assertiveness: A Literature Review. J Nurs Care. 2014;3(194):2167-1168.

3- Rahmatizadeh M, Koolaee AK, Falsafinejad MR, Yaghobee Z. Effectiveness of emotional intelligence on assertiveness and self-esteem in high school girl students. Middle East Journal of Psychiatry and Alzheimers. 2016 Jun;7(1):10-4.

4- Ames D. Pushing up to a point: Assertiveness and effectiveness in leadership and interpersonal dynamics. Research in organizational behavior. 2009 Dec 31;29:111-33.

5- Deltsidou A. Undergraduate nursing students' level of assertiveness in Greece: A questionnaire survey. Nurse education in practice. 2009 Sep 30;9(5):32230.

6- Hopkins, J. Nursing assertiveness and human needs, 4th ed, USA: $2012 ; 204-205$.

7- Begley CM, Glacken M. Irish nursing students' changing levels of assertiveness during their preregistration programme. Nurse Education Today. 2004 Oct 31;24(7):501-10.

8- Barnette V. Assertive communication. University Counseling Service. The University of Iowa.(2009)

9- Pervaiz KA, Shepherd CD. Innovation Management: Context, strategies, systems and processes. England: Pearson Education Limited. 2010.

10- Mahmoudirad G, Ahmadi F, Vanaki Z, Hajizadeh E. Assertiveness process of Iranian nurse leaders: A grounded theory study. Nursing \& health sciences. 2009 Jun 1;11(2):120-7.

11- Timmins F, McCABE CA. How assertive are nurses in the workplace? A preliminary pilot study. Journal of nursing management. 2005 Jan 1;13(1):61-7.

12- Antai-Otong D, Dauenheimer MT. Psychiatric nursing: Biological and behavioral concepts. WB Saunders,; 1995. Ch 32: P 661.

13- Mc Cabe C, Timmins F. Teaching assertiveness to undergraduate nursing students. Nurse Education in Practice. 2003 Mar 31;3(1):30-42.

14- Eldeeb GA.: Assertiveness and stress among undergraduate nursing students at menofyia university . Journal Of Natural Sciences Research . 2014; 4 (4): 30-37.

15- Maheshwari SK, Kaur G. Correlation of assertive behavior with communication satisfaction among 
nurses. Journal of Health, Medicine, and Nursing. 2015;14:68-76. Jan 28.

16- Abdel-Aleem M. Factors affecting assertiveness among head nurses and staff nurses. Unpublished Master Thesis). Faculty of Nursing. Suez Canal University. 2007; . 74-76

17- El Din S D. Factors affecting assertive behavior of nurses working in different units in Cairo university hospitals unpublished master thesis, Cairo University, Egypt.. 2003; Pp 58-65.

18- Ahmed AS. Assertiveness and job satisfaction among nursing personnel at Zagazig University hospital Unpublished Master degree, Thesis in nursing administration, Faculty of nursing, Zagazig University. 2009; Pp. 61-65.

19- Sanders RL. Assertive communication skills with nurses in a rural setting. University of Wyoming; 2007

20- Abdel-Khalek, M. Level of assertiveness and nursing performance; Unpublished Master degree, Thesis in Faculty of nursing, Cairo University; (2010) . Pp 4-10.
21- Eskin M. Self-reported assertiveness in Swedish and Turkish adolescents: A cross $\square$ cultural comparison. Scandinavian Journal of Psychology. 2003 Feb 1;44(1):7-12.

22- Looker ED, Magee PA. Gender and work: The occupational expectations of young women and men in the 1990s. Gender Issues. 2000 Mar $1 ; 18(2): 74-88$.

23- Kilkus, S. Assertiveness among Professional Nurses, Journal of Advanced Nursing. 2010 18(8); P 1324-1330.

24- Khalil, D. Assertive behavior among nursing working in critical units at ain shims university hospitals. Master degree, thesis in nursing psychiatric, Faculty of Nursing, Ain Shims University. (2011) .Pp 66-77.

25- Abed G A, El-Amrosy S H, Atia M M.. The Effect of Assertiveness Training Program on Improving Self-Esteem of Psychiatric Nurses. Journal of Nursing Science. 2015; 1 (1): 1- 8. 